Research Article

\title{
Experimental evaluation of analgesic activity of PPAR $\gamma$ agonists: pioglitazone and rosiglitazone
}

\author{
Chetanraj G. Bhamare*, Sudhir L. Padwal, Vijay M. Motghare, Rushikesh P. Deshpande, \\ Rakesh R. Pore, Suvarna S. Rathod, Harshal N. Pise
}

Department of Pharmacology, S R T R Government Medical College, Ambajogai- 431517, Maharashtra, India

Received: 9 November 2013 Accepted: 17 November 2013

\section{*Correspondence to:}

Dr. Chetanraj G Bhamare,

Email: chetanraj1608@gmail.com

(C) 2014 Bhamare CG et al. This is an open-access article distributed under the terms of the Creative Commons Attribution NonCommercial License, which permits unrestricted noncommercial use, distribution, and reproduction in any medium, provided the original work is properly cited.

\begin{abstract}
Background: To evaluate analgesic activity of pioglitazone and rosiglitazone by tail flick method in rats and acetic acid induced writhing method in mice.

Methods: Albino wistar rats of either sex weighing 180-200 g and Swiss mice weighing 25-30 g were used. Study was conducted after approval from the Institutional Animal Ethics Committee. The tail flick method in rats described by D'Amour and Smith (1941) and acetic acid induced writhing in mice were used. The dose of pioglitazone and rosiglitazone were $20 \mathrm{mg} / \mathrm{kg}$ and $10 \mathrm{mg} / \mathrm{kg}$ respectively.

Results: In tail flick method of analgesia, both, pioglitazone and rosiglitazone have analgesic activity which was statistically comparable to aspirin. In acetic acid induced writhing model of analgesia, the action of pioglitazone and rosiglitazone was significantly greater than the control group but it was less when compared to aspirin.

Conclusions: Analgesic activity of pioglitazone and rosiglitazone was comparable to aspirin in tail flick model of analgesia in rats while it was significantly less when compared to tramadol. Analgesic activity of pioglitazone and rosiglitazone was significantly less than aspirin in acetic acid induced writhing method.
\end{abstract}

Keywords: Analgesic activity, Pioglitazone, Rosiglitazone, Tail flick method, Acetic acid induced writhing method

\section{INTRODUCTION}

International association for the study of pain (IASP) has defined pain as "an unpleasant sensory and emotional experience associated with actual or potential tissue damage, or described in terms of such damage". ${ }^{1}$ It is not just a physical sensation but also an emotional experience. It varies from person to person and in the same person from time to time. ${ }^{2}$ The term nociception includes all neuronal processes for the recognition of a potentially or actually damaging stimulus. In a neuropharmacologic experiment an afferent neuron is normally labelled nociceptive if it shows a strong response only to stimuli that produce pain in human subject and equivalent reaction in animals. ${ }^{3}$ Peroxisome proliferator-activated receptors (PPARs) are ligand activated transcription factor belonging to a nuclear hormone receptor superfamily, containing three iso-forms $(\alpha, \beta / \delta$, and $\gamma)$. Pioglitazone and rosiglitazone are known to act through PPAR $\gamma$ receptors. These ligands are clinically used for treatment of type 2 diabetes and hyperlipidemia. ${ }^{4}$

In recent years, it has emerged that administration of PPAR $\gamma$ ligands reduces inflammatory pain and neuropathic pain. ${ }^{5}$ They have been reported to regulate inflammatory response; but the extent of this regulation, and indeed its direction, are controversial. Hence this study was planned with the aim to evaluate analgesic (antinociceptive) activity of pioglitazone and rosiglitazone by tail flick method in rats and acetic acid induced writhing method in mice. 


\section{METHODS}

\section{Ethics committee permission}

Study was conducted after approval from the institutional animal ethics committee (Approval letter no. 519 dated $18 / 11 / 2010$ ), which is an approved body by CPCSEA (Committee for the Purpose of Control and Supervision of Experiments on Animals).

\section{Experimental Animals}

Albino wistar rats of either sex weighing 180-200 $\mathrm{g}$ and Swiss mice weighing 25-30 g were used. The rats and mice were grouped in separate cages with six animals in each cage. They were maintained in a colony room at ambient temperature of $23 \pm 1^{\circ} \mathrm{C}$ with help of air conditioner and enough humidity on a 12 hour light dark cycle. They had free access to food and water. Similar conditions were provided in laboratory while performing experiments. Study was conducted during the day time (between 10.00 to $18.00 \mathrm{hrs}$ ).

\section{Screening of analgesic activity}

Screening of analgesic activity: Since false positive results are sometimes obtained, Discordination test by Collier (1949) was carried out to exclude such possibilities. The rats were placed on a slowly rotating drum covered with a wire mesh. The rats that fall off were considered discordinated and were discarded from screening programme.

\section{Tail flick method in rats}

Anti-nociceptive activity was assessed by tail - flick response method by analgesiometer; originally described by D'Amour and Smith in $1941 .^{6}$ Animals were divided into groups ( $n=6$ in each group) (Table 1).

Table 1: Animal grouping in tail flick method.

\begin{tabular}{|c|c|c|}
\hline Group & Drug given & Dose \\
\hline Control & Normal saline & $\begin{array}{l}2 \mathrm{ml} / \mathrm{kg} \\
\text { (p.o.) }\end{array}$ \\
\hline Pioglitazone & $\begin{array}{l}\text { Pioglitazone dissolved in } \\
\text { carboxymethyl cellulose }\end{array}$ & $\begin{array}{l}20 \mathrm{mg} / \mathrm{kg} \\
\text { (p.o.) }\end{array}$ \\
\hline Rosiglitazone & $\begin{array}{l}\text { Rosiglitazone dissolved in } \\
\text { carboxymethyl cellulose }\end{array}$ & $\begin{array}{l}10 \mathrm{mg} / \mathrm{kg} \\
\text { (p.o.) }\end{array}$ \\
\hline Aspirin & $\begin{array}{l}\text { Aspirin dissolved in } \\
\text { carboxymethyl cellulose }\end{array}$ & $\begin{array}{l}300 \mathrm{mg} / \mathrm{kg} \\
\text { (p.o.) }\end{array}$ \\
\hline Tramadol & Tramadol & $\begin{array}{l}10 \mathrm{mg} / \mathrm{kg} \\
\text { (i.p.) }\end{array}$ \\
\hline
\end{tabular}

Observations were taken by placing the middle part of the tail on the radiant heat source, that is, heated nichrome wire. The strength of the current passing through the naked nichrome wire was kept constant at 6 amps. Small flickering movements were ignored, and squeak (a high pitch sound uttered by rats) or a sharp withdrawal of the tail called as "tail - flick response" was taken as the endpoint of the experiment. The time between placing the tail of the rat on the radiant heat source and the sharp withdrawal of the tail was recorded as "reaction time". A day prior to the actual experiments, the animals were subjected to the same experiments so as to familiarize them with the study procedure.

During experimentation each animal was tested 4 times at the interval of 5 minutes between the two responses while taking the observations. The animals usually responded sluggishly and took little longer time when nociceptive stimulus was applied for the first time. Hence the first reading was discarded and the mean of the next three readings was taken as "basal latency". The screened animals were marked and kept in different cages. A cutoff time of 10 seconds was imposed in all sets of experiments taken as maximum latency so as to rule out thermal injury while noting down the reaction time. Reaction time was noted with the help of stop watch. In all the groups, tail-flick test was performed prior to drug administration and at the end of 30,60, 90 and 120 minutes after drug administration and the reaction time at each time interval (test latency) was calculated. Percentage analgesia was calculated by using following formula:

$$
\% \text { Analgesia }=\text { M.P.E. }=\frac{\text { T. L. }- \text { B. L. }}{\text { M. L. }- \text { B. L }} \times 100
$$

\section{Where,}

M.P.E. = Maximum possible effect.

M.L. = Maximum latency or cut-off time

T.L. = Test latency or latency at the end of particular period of time

B.L. = Basal latency or control latency

\section{Acetic acid induced writhing in mice}

The writhing model represents a chemical nociceptive test based on the induction of peritonitis like condition in animals by injecting irritant substances intraperitoneally. ${ }^{7}$ Mice were kept individually in the test cage before acetic acid injection and habituated for 30 minutes. Animals were divided into groups ( $n=6$ in each group) (Table 2).

Table 2: Acetic acid induced writhing method.

\begin{tabular}{|c|c|c|}
\hline Group & Drug given & Dose \\
\hline Control & Normal saline & $\begin{array}{l}2 \mathrm{ml} / \mathrm{kg} \\
\text { (p.o.) }\end{array}$ \\
\hline Pioglitazone & $\begin{array}{l}\text { Pioglitazone dissolved in } \\
\text { carboxymethyl cellulose }\end{array}$ & $\begin{array}{l}20 \mathrm{mg} / \mathrm{kg} \\
\text { (p.o.) }\end{array}$ \\
\hline Rosiglitazone & $\begin{array}{l}\text { Rosiglitazone dissolved in } \\
\text { carboxymethyl cellulose }\end{array}$ & $\begin{array}{l}10 \mathrm{mg} / \mathrm{kg} \\
\text { (p.o.) }\end{array}$ \\
\hline Aspirin & $\begin{array}{l}\text { Aspirin dissolved in } \\
\text { carboxymethyl cellulose }\end{array}$ & $\begin{array}{l}300 \mathrm{mg} / \mathrm{kg} \\
\text { (p.o.) }\end{array}$ \\
\hline
\end{tabular}


After 30 minutes of drug administration, $0.1 \mathrm{ml}$ of $1 \%$ acetic acid solution was given to mice intraperitoneally (i.p.).The mice were placed individually under the glass beakers and five minutes were allowed to elapse. The

After 30 minutes of drug administration, $0.1 \mathrm{ml}$ of $1 \%$ acetic acid solution was given to mice intraperitoneally (i.p.).The mice were placed individually under the glass beakers and five minutes were allowed to elapse. The mice were then observed for a period of ten minutes and the numbers of writhes were recorded for each animal. For scoring purposes, a writhe is indicated by stretching of the abdomen with simultaneous stretching of at least one hind limb. The following formula was used to calculate percentage inhibition.
$\%$ Inhibition $=\frac{\text { No. of writhes in control group }}{\text { No. of writhes in control group }} \times 100$

\section{Statistical Analyses}

Data was analyzed by using Graph Pad Prism software version 5.01. Comparison between different groups was done by one way ANOVA followed by Bonferroni post test for comparison between multiple groups. The ' $p$ ' value less than 0.05 was considered statistically significant.

\section{RESULTS}

Data of the basal latency (i.e. basal mean reaction time) was statistically analyzed and compared in all the five groups in the tail flick model of analgesia in rats (Table 3).

Table 3: Effects of different drugs on nociception in tail flick model of analgesia in rats.

\begin{tabular}{|llllll|}
\hline Groups & $\begin{array}{l}\text { Basal latency } \\
\text { (seconds) }\end{array}$ & $\begin{array}{l}\text { At } 30 \mathrm{~min} \\
\text { (seconds) }\end{array}$ & $\begin{array}{l}\text { At } 60 \mathrm{~min} \\
\text { (seconds) }\end{array}$ & $\begin{array}{l}\text { At } 90 \text { min } \\
\text { (seconds) }\end{array}$ & $\begin{array}{l}\text { At } 120 \text { min } \\
\text { (seconds) }\end{array}$ \\
\hline $\begin{array}{l}\text { Control } \\
\text { (Normal saline } \\
\text { 2ml/ kg p.o.) }\end{array}$ & $3.848 \pm 0.275$ & $4.187 \pm 0.191$ & $4.092 \pm 0.345$ & $4.230 \pm 0.268$ & $3.883 \pm 0.251$ \\
\hline $\begin{array}{l}\text { Aspirin (300 } \\
\text { mg/kg p.o.) }\end{array}$ & $3.994 \pm 0.131$ & $7.747 \pm 0.412^{* * \# @}$ & $6.685 \pm 0.345^{* *}$ & $5.795 \pm 0.276^{* *}$ & $5.000 \pm 0.213$ \\
\hline $\begin{array}{l}\text { Tramadol } \\
\text { (10 mg/kg i.p.) }\end{array}$ & $4.842 \pm 0.276$ & $8.392 \pm 0.3171^{* * \# @}$ & $9.192 \pm 0.316^{* * \# @}$ & $6.968 \pm 0.259^{* * \#}$ & $5.865 \pm 0.112^{* * \#}$ \\
\hline $\begin{array}{l}\text { Pioglitazone } \\
\text { (20mg/kg p.o.) }\end{array}$ & $3.988 \pm 0.174$ & $5.23 \pm 0.228$ & $6.790 \pm 0.432^{* * @}$ & $5.023 \pm 0.259$ & $4.168 \pm 0.293$ \\
\hline $\begin{array}{l}\text { Rosiglitazone } \\
\text { (10mg/kg p.o.) }\end{array}$ & $3.680 \pm 0.125$ & $4.49 \pm 0.303$ & $5.238 \pm 0.191$ & $7.050 \pm 0.177^{* * \#}$ & $4.823 \pm 0.385$ \\
\hline
\end{tabular}

Values are mean \pm S.E.M. (Standard Error of Mean), $n=6$ in each group

** $\mathrm{p}<0.01$ when compared to control

\# $\mathrm{p}<0.05$ when compared to pioglitazone

@ $\mathrm{p}<0.05$ when compared to rosiglitazone

The analgesic effect in pioglitazone group was observed at 60 minutes. It was statistically significantly more when compared with the control group $(\mathrm{p}<0.01)$ and also with rosiglitazone group $(\mathrm{p}<0.05)$ and comparable to tramadol group $(\mathrm{p}>0.05)$ at 60 minute interval, then decreased by 120 minutes as can be seen from 120 minutes latency readings. At 120 minute interval, the analgesic effect of pioglitazone was more as compared to control group, but was statistically not significant. The analgesic effect in pioglitazone group was less as compared to aspirin at 30 minute interval, comparable at all the other intervals as there was no statistically significant difference in the mean latency time. Analgesic effect at 120 minutes was significantly less than that of tramadol $(\mathrm{p}<0.05)$.

In rosiglitazone group, 30 minute latency was comparable to control group $(\mathrm{P}>0.05)$ but it was significantly less as compared to aspirin group $(\mathrm{P}<0.05)$ and tramadol group $(p<0.05)$. There was progressive increase in the analgesic activity of rosiglitazone which was maximum at 90 minutes and was statistically significantly more when compared with the control group $(\mathrm{p}<0.01)$ and also with pioglitazone group $(\mathrm{p}<0.05)$ and comparable to tramadol group $(p>0.05)$ at this interval. The analgesic activity then decreased by 120 minutes, as was evident by latency time, and was comparable to pioglitazone and control group $(p>0.05)$. The analgesic activity of tramadol was maximum at all time intervals. Data of the percentage maximum possible effect of different drugs at different time intervals was statistically analyzed (Table 4).

At 30 minutes, the maximum possible effect of pioglitazone and rosiglitazone was significantly less $(p<0.05)$ than tramadol and aspirin groups. The maximum possible effect of pioglitazone and rosiglitazone was comparable $(p>0.05)$ to each other. 
At 60 minute interval, mean Maximum Possible Effect of rosiglitazone group was less than that of pioglitazone and aspirin, but the difference was not statistically significant. Then mean Maximum Possible Effect of rosiglitazone and aspirin group was comparable with no statistically significant difference. At 60 minute, the Maximum Possible Effect of tramadol was the largest and significantly greater that the other three groups $(\mathrm{p}<0.01)$. Pioglitazone showed maximum MPE (Maximum Possible Effect) at 60 minute interval than at other intervals.

At 90 minute interval, the mean of Maximum Possible Effect of pioglitazone was significantly less than tramadol $(p<0.01)$. Maximum Possible Effect of tramadol was found to be significantly more than aspirin in this interval $(p<0.05)$ while comparable with rosiglitazone group ( $>0.05$ ). Rosiglitazone showed maximum MPE amongst the three groups at 90 minute interval.

At 120 minute interval, the difference between mean Maximum Possible Effect of all the groups was decreased. It was comparable $(\mathrm{p}>0.05)$ in rosiglitazone and aspirin groups. Tramadol showed largest Maximum Possible Effect amongst all the groups at this time interval and was significantly more than pioglitazone group $(\mathrm{p}<0.01)$.

Table 4: Maximum possible effect of drugs in tail flick method of analgesia in rats.

\begin{tabular}{|c|c|c|c|c|}
\hline \multirow{2}{*}{$\begin{array}{l}\text { Drugs and doses }(\mathrm{mg} / \mathrm{kg}) \\
(\mathrm{n}=6 \text { animals) }\end{array}$} & \multicolumn{4}{|c|}{ \% Maximum Possible Effect in seconds } \\
\hline & After 30 min & After $60 \mathrm{~min}$ & After 90 min & After $120 \mathrm{~min}$ \\
\hline Control (Normal saline $2 \mathrm{ml} / \mathrm{kg}$ p.o.) & - & - & - & - \\
\hline Aspirin $(300 \mathrm{mg} / \mathrm{kg}$ p.o. $)$ & $61.10 \pm 6.984^{*}$ & $42.44 \pm 7.057^{\# \#}$ & $25.92 \pm 6.719^{\#}$ & $17.40 \pm 5.359$ \\
\hline Tramadol (10 mg/kg p.o.) & $71.62 \pm 6.250$ & $86.80 \pm 4.773$ & $47.56 \pm 3.56$ & $32.00 \pm 2.622$ \\
\hline Pioglitazone (20mg/kg p.o.) & $17.64 \pm 4.290^{\# \#}$ & $45.57 \pm 7.876^{\# \#}$ & $14.04 \pm 2.771^{\text {*\#\# }}$ & $7.36 \pm 2.433^{\# \#}$ \\
\hline Rosiglitazone (10mg/kg p.o.) & $13.52 \pm 3.326^{\# \#}$ & $21.77 \pm 4.164^{\# \#}$ & $47.42 \pm 3.585$ & $21.04 \pm 5.162$ \\
\hline
\end{tabular}

Values are Mean \pm S.E.M, $\mathrm{n}=6$ in each group.

$* \mathrm{p}<0.05$ when compared to rosiglitazone group

$\# \mathrm{p}<0.05$ when compared to tramadol group

$\# \# \mathrm{p}<0.01$ when compared to tramadol group

Result data of acetic acid induced writhing method shows that the total number of writhes in 10 minutes was highest in control group $(31.83 \pm 1.108)$ and lowest in aspirin group $(5.333 \pm 0.667)$. Number of writhes in 10 minutes in pioglitazone and rosiglitazone group was significantly less than control group $(\mathrm{p}<0.05)$ but was significantly more when compared to aspirin $(\mathrm{p}<0.05)$. Percentage analgesia was maximum in aspirin group (83.18\%) and was least in pioglitazone group $(47.56 \%$ ) (Table 5 and Figure 1).

Table 5: Effect of different drugs in acetic acid induced writhing models in mice.

\begin{tabular}{|lll|}
\hline Groups (n=6 animals) & Number of writhes (in $\mathbf{1 0}$ min) & Percentage analgesia \\
\hline Control (Normal saline $2 \mathrm{ml} / \mathrm{kg}$ p.o.) & $31.83 \pm 1.108$ & - \\
\hline Pioglitazone $(20 \mathrm{mg} / \mathrm{kg}$ p.o.) & $16.67 \pm 1.333^{* \#}$ & $47.56 \%$ \\
\hline Rosiglitazone $(10 \mathrm{mg} / \mathrm{kg}$ p.o.) & $9.667 \pm 0.843^{* \#}$ & $69.57 \%$ \\
\hline Aspirin (300 mg/kg p.o.) & $5.333 \pm 0.667^{*}$ & $83.18 \%$ \\
\hline
\end{tabular}

Values are mean \pm S.E.M $; n=6$ in each group

$* \mathrm{p}<0.05$ when compared to control group

$\# \mathrm{p}<0.05$ when compared to aspirin group.

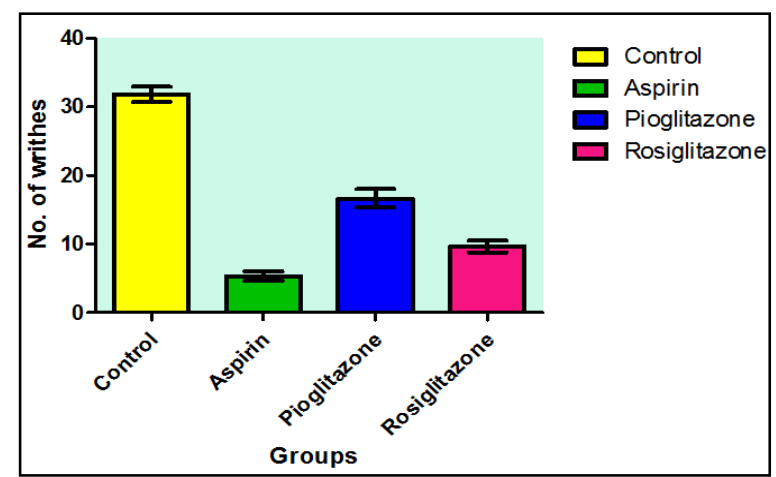

Figure 1: Writhing test in mice.

\section{DISCUSSION}

Thiazolidinedione exert their insulin-sensitising and hypoglycaemic effects through stimulation of PPAR $\gamma$. TZD-induced stimulation of PPAR $\gamma$ results in an alteration in the transcription of several genes involved in glucose and lipid utilisation and energy balance such as GLUT4 glucose transporter and fatty acid transporter protein .The involvement of PPAR $\gamma$ in the pharmacological effects of TZDs has been supported by studies showing that their binding affinity to PPAR $\gamma$ closely parallels their in vivo hypoglycaemic potency. ${ }^{8}$

The tail flick method of analgesia is very effective in estimating the efficacy and potency of centrally acting 
analgesic drugs. In our study, the results of this method showed that both, pioglitazone and rosiglitazone have analgesic activity which was statistically comparable to aspirin.

Pioglitazone showed maximum analgesic activity at 60 minute interval and then the effect diminished but was comparable to aspirin at 120 minute interval. Percentage analgesic effect of pioglitazone was $45.57 \%$.The effect of rosiglitazone was $13.52 \%$ at 30 minutes and thereafter increased gradually and was maximum at 90 minute interval. The effect at 90 minute was found to be almost similar to tramadol. Percentage analgesic effect of rosiglitazone was $47.42 \%$ at 90 minute.

This shows that the pain threshold increased significantly during the period of observation in each of the four drug treated groups with maximum effect observed in tramadol group at all observation times. Tail flick method mainly evaluates the analgesic activity of centrally active drugs. Hence tramadol, which acts by central mechanism, has shown the maximum activity. Rosiglitazone showed activity comparable to tramadol in at least one observation interval. Various authors have suggested that the site of action of pioglitazone and rosiglitazone is at the level of spinal cord and hence they have a central mechanism of action. Pioglitazone is a particularly exciting candidate for PPAR $\gamma$ analgesia that can cross the blood- brain barrier to exert central nervous system (CNS) actions. ${ }^{9,10}$ Our findings are in accordance with them. Though aspirin has a central component of action it predominantly produces analgesia through a peripheral action. Hence maximum analgesic action of aspirin cannot be evident in the tail flick model of analgesia.

In acetic acid induced writhing model of analgesia, the action of pioglitazone and rosiglitazone was significantly greater than the control group but it was less when compared to aspirin. Percentage analgesia with both pioglitazone and rosiglitazone was less than $70 \%$ and it was more than $80 \%$ only with aspirin treated animals. In this method, compounds with percentage analgesia of less than $70 \%$ are considered to have minimal analgesic activity. ${ }^{11}$ The writhing response induced by acetic acid is a sensitive procedure to establish peripherally acting analgesics. As the acetic acid induced writhing method mainly evaluates peripherally acting analgesics, maximum analgesic activity of aspirin was observed in this model while the analgesic action of both pioglitazone and rosiglitazone was significantly less as compared to aspirin. The action of pioglitazone and rosiglitazone was comparable to aspirin in the tail flick model of antinociception but not in acetic acid induced writhing method. This suggests that peripheral pain mechanisms may not be significantly affected by these two drugs.

Our study is in accordance with Oliveira AC et al $(2007)^{12}$ who observed that pioglitazone $(1-50 \mathrm{mg} / \mathrm{kg}$ i.p.) inhibited the second phase of formaldehyde induced nociceptive response in mice and Churi SB et al $(2008)^{10}$ who concluded that ligand-induced activation of spinal PPAR $\gamma$ rapidly reverses nerve injury-induced mechanical allodynia. Single injection of either a natural (15-deoxyprostaglandin $\mathbf{J} 2,15 \mathrm{~d}-\mathrm{PGJ} 2$ ) or synthetic (rosiglitazone) PPAR $\gamma$ agonist dose-dependently decreased mechanical and cold hypersensitivity. Jia $\mathrm{H}$ et al (2010) ${ }^{9}$ demonstrated that preventive administration of pioglitazone would dose-dependently attenuate the mechanical hyperalgesia in L5 spinal nerve transaction rats. The anti-nociceptive effect of pioglitazone would be correlated with the reduction of production of TNF and IL-1 through inhibition of NF-B in the brain.

In conclusion, Pioglitazone and rosiglitazone showed statistically significant analgesic activity in tail flick model indicating a central mechanism of action for analgesic activity, but did not show any statistically significant activity in acetic acid induced writhing model thus showing a lack of peripheral action.

Funding: No funding sources

Conflict of interest: None declared

Ethical approval: Approval was taken from the institutional animal ethics committee

\section{REFERENCES}

1. Pain terms: a list with definitions and notes on usage. Recommended by the IASP Subcommittee on Taxonomy. Pain. 1979;6(3):249.

2. Rajagopal MR. Pain- Basic consideration. Indian $\mathbf{J}$ Anaesth. 2006;50(5):331-4.

3. Stuky CL, Gold MS, Zhang XU. Mechanism of pain. PNAS. 2001;98(21):1185-6.

4. Yki-Jarvinen H. Thiazolidinediones. N Engl J Med. 2004;351:1106-18.

5. Fehrenbacher JC, Lo Verme J, Clarke W, Hargreaves KM, Piomelli D, Taylor BK. Rapid Pain Modulation with Nuclear Receptor Ligands. Brain Res Rev. 2009;60:114-24.

6. Parmar NS, Prakash S. Evaluation of analgesics, anti-inflammatory and anti-pyretic activity. In: Parmar NS, editor. Screening Methods in Pharmacology. New Delhi, India: Narosa Publishing House; 2006: 232-233.

7. Parmar NS, Prakash S. Evaluation of analgesics, anti-inflammatory and anti-pyretic activity. In: Parmar NS, editor. Screening Methods in Pharmacology, New Delhi, India: Narosa Publishing House; 2006: 225-226.

8. Abdelrahman M, Sivarajah A, Thiemermann C. Beneficial effects of PPAR-gamma ligands in ischemia-reperfusion injury, inflammation and shock. Cardiovasc Res. 2005;65:772-81.

9. Jia H, Zhu S, Ji Q, Hui K, Duan M, Xu J, et al. Repeated Administration of Pioglitazone Attenuates Development of Hyperalgesia in a Rat Model of Neuropathic Pain. Exp Clin Psychopharmacol. 2010;18(4):359-65. 
10. Churi SB, Abdel-Aleem OS, Tumber KK, ScuderiPorter H, Taylor BK. Intrathecal Rosiglitazone Acts at Peroxisome Proliferator-Activated Receptor- $\gamma$ to Rapidly Inhibit Neuropathic Pain in Rats. J Pain. 2008;9(7):639-49.

11. Vogel HG. Analgesic, Anti-inflammatory and antipyretic activity. In: Vogel HG, editor. Drug Discovery and Evaluation: Pharmacological Assays. $2^{\text {nd }}$ ed. Berlin Germany: Springer-Verlag Publications; 2002: 767.
12. Oliveira AC, Bertollo CM, Rocha LT, Nascimento EB Jr, Costa KA, Coelho MM. Antinociceptive and antiedematogenic activities of fenofibrate, an agonist of PPAR alpha, and pioglitazone, an agonist of PPAR gamma. Eur J Pharmacol. 2007;561(1-3):194 201.

doi:10.5455/2319-2003.ijbcp20140208

Cite this article as: Bhamare CG, Padwal SL, Motghare VM, Deshpande RP, Pore RR, Rathod SS, Pise HN. Experimental evaluation of analgesic activity of PPAR $\gamma$ agonists: pioglitazone and rosiglitazone. Int J Basic Clin Pharmacol 2014;3:8691. 